\title{
Concepções de Justiça Compartilhadas: a Negociação pelos Danos Espirituais ao Povo Mẽbêngôkre Kayapó ${ }^{1}$
}

\section{Shared Conceptions of Justice: Negotiating for Spiritual Damages to the Mẽbêngôkre Kayapó People}

\author{
Lucas Cravo de Oliveira \\ Universidade de Brasília, Brasília, Distrito Federal, Brasil \\ Douglas Antônio Rocha Pinheiro \\ Universidade de Brasília, Brasília, Distrito Federal, Brasil
}

\section{Ronaldo Joaquim da Silveira Lobão}

Universidade Federal Fluminense, Niterói, Rio de Janeiro, Brasil

\section{RESUMO}

Esta pesquisa busca compreender a maneira como o constitucionalismo brasileiro cria possibilidades no sistema de justiça para se administrar um conflito no qual se entrecruzam diversas concepções de justiça, tomando por base um estudo de caso sobre o processo extrajudicial decorrente da queda do Voo 1907 da empresa aérea Gol na Terra Indígena Capoto-Jarina, do qual decorreu uma indenização diferenciada para o povo indígena Mẽbêngôkre Kayapó. As partes afetadas estabeleceram um acordo por danos culturais, uma categoria conceitual discutida ao longo do processo com outras denominações, tais como danos socioculturais ou danos espirituais. As estratégias de

\footnotetext{
1 Este artigo científico é desdobrado de uma pesquisa realizada em âmbito de mestrado acadêmico. O autor, Lucas Cravo, foi orientado pelos professores Douglas Pinheiro (UnB) e Ronaldo Lobão (UFF) no Programa de Pós-Graduação em Direito da Universidade de Brasília, disso resultou-se a dissertação Fronteiras improváveis entre tempos e direitos: constitucionalismo compartilhado entre os sistemas de justiça estatal e Mẽbêngôkre Kayapó no acidente do Gol 1907 (2020). Para o seu desenvolvimento, foi concedido financiamento da Coordenação de Aperfeiçoamento de Pessoal de Nível Superior (CAPES) e da Fundação de Apoio à Pesquisa do Distrito Federal (FAPDF). Os autores não atuaram nos autos do processo analisado. Suas relações com o caso se dão exclusivamente no âmbito do interesse de pesquisa.
} 
pesquisa adotadas são inspiradas em metodologias características da micro-história e da antropologia jurídica, o que nos permitiu refletir sobre suas convergências, distinções e incompletudes com o fim de compreender um problema do direito. Trata-se de uma pesquisa empírica que analisa um acordo organizado fora das cortes judiciárias, verificando fontes documentais e narrativas dos atores sociais envolvidos. A partir do trabalho de campo em uma investigação interdisciplinar, descrevemosalgumas das contingências de se administrar tempos e direitos culturalmente diversos.

Palavras-chave: Pesquisa empírica, Micro-história, Antropologia jurídica, Danos culturais, Danos espirituais.

\section{ABSTRACT}

This research seeks to understand how the Brazilian constitutionalism creates possibilities in the justice system to manage a conflict in which several conceptions of justice intersect, based on a case study of the out-of-court process resulting from the crash of Gol airline Flight 1907 in the Capoto-Jarina Indigenous Land, which resulted in a specific compensation for the Mẽbêngôkre Kayapó indigenous people. The affected parties established an agreement for cultural damages, a conceptual category discussed throughout the process with other denominations, such as sociocultural or spiritual damages. The research strategies adopted are inspired by methodologies characteristic of microhistory and legal anthropology, which allowed us to reflect on their convergences, distinctions and incompleteness in order to understand a problem of law. This is an empirical research that analyzes an agreement made outside the Judiciary, checking documentary sources and narratives of the social actors involved. Based on fieldwork in an interdisciplinary investigation, we describe some of the contingencies of managing culturally diverse times and rights.

Keywords: Empirical research, Microhistory, Legal anthropology, Cultural damage, Spiritual damage.

\section{INTRODUÇÃO}

Neste estudo de caso, optamos por utilizar instrumentos, orientações e abordagens da história e da antropologia para compreender um problema do direito. “[...] os conceitos são instrumentos frios tomados da bagagem da ciência acadêmica: eles são úteis na interpretação, mas é apenas nessa função que adquirem realidade concreta e especificidade" (LEVI, 1992, p. 143). Com aportes específicos em exercícios da micro-história e da antropologia jurídica, 
esboçamos questões que emergem diante do constitucionalismo brasileiro. O mundo empírico é dinâmico, plural, diverso. O ordenamento jurídico é chamado para dar respostas aos conflitos que não necessariamente foram previstos nas normas. Ao menos não com alto grau de precisão. Compreender com profundidade casos inesperados demanda estratégias que escapem à exclusividade da miopia jurídica.

O documento principal que dá corpo ao arquivo produzido em relação ao caso Gol é o Inquérito Civil (IC) 1.20.004.000070/2016-55². É nele que estão reunidos os pareceres técnicos realizados pela perícia antropológica do MPF, o termo do acordo extrajudicial e o registro das fases pelas quais este processo extrajudicial se desdobrou. Optamos por apresentar as reflexões desdobradas do trabalho de campo realizado por Lucas Cravo ao longo do ano de 2019 e no início de 2020, o qual incluiu entrevistas e uma visita curta à Terra Indígena Capoto-Jarina. Sobre a análise do acervo documental, destacamos o Termo de Acordo extrajudicial.

O trabalho se divide em duas seções. Na primeira apresentamos as percepções que os atores sociais têm acerca desta administração de conflito e uma análise sobre o texto do acordo. Na segunda, elaboramos reflexões metodológicas acerca das potencialidades de se cruzar abordagens empíricas próprias da antropologia e da micro-história, as quais entendemos como confluentes, para se compreender um problema do direito.

Optamos por essa divisão, inspirados na abordagem seguida por Ronaldo Lobão (2010) em sua tese doutoral, a qual foi influenciada por Louis Dumont (1978), ao segmentá-la em três partes: reunir, compreender e reconstruir ${ }^{3}$. Nesta pesquisa, em princípio descrevemos o caso a partir do trabalho de campo e do arquivo documental selecionado, em um ato de reunir os dados. Na seção seguinte, mesclamos o esforço de compreender e reconstruir os dados confrontados com as nossas percepções analíticas, destacando-se a preocupação acerca da pesquisa empírica e suas possibilidades interdisciplinares ao tratar de um problema gerado no âmbito do sistema de justiça.

$2 \mathrm{O}$ MPF é uma instituição do sistema de justiça habilitada a promover o inquérito civil e a ação civil pública pelo próprio texto constitucional, conforme prescrição do art. 129, III, da CF. A utilização deste instrumento de atuação é regulada pela Lei n. 7.347/1985, pela Lei Complementar n. 75/1993 e pela Resolução n. 87 do Conselho Superior do Ministério Público Federal.

3 Sobre essa proposta integral, ver: LOBÃO, Ronaldo. Cosmologias políticas do neoliberalismo: como uma política pública pode se transformar em uma política do ressentimento. Niterói: Editora da Universidade Federal Fluminense, 2010. 


\section{AS NARRATIVAS DO PROCESSO: PERCEPÇÕES DOS ATORES SOCIAIS E 0 ACORDO EXTRAJUDICIAL}

\section{Ministério Público Federal}

No dia 13 de março de 2019, o Procurador da República Wilson Rocha Fernandes Assis foi convidado a falar, na Câmara Técnica Indígena e Povos e Comunidades Tradicionais (CT-IPCT), sobre o caso da queda do avião da Gol, no qual atuou como o membro do Ministério Público Federal responsável por conduzi-lo. Antes de iniciar a apresentação, Carolina Molina (coordenadora da CT-IPCT e servidora efetiva da Secretaria de Governo da Presidência da República) explica para o Wilson Assis quais eram as funções da CT-IPCT. Ela diz que o convite para ele vem com a necessidade de que sejam pensadas as indenizações coletivas para os povos e as comunidades tradicionais no aspecto material e no imaterial.

Wilson Assis inicia sua fala explicando que trabalhou em Barra do Garças, um município do estado do Mato Grosso, até 2017. A Terra Indígena (TI) Capoto-Jarina está nas atribuições da Procuradoria da República que atua neste espaço. Ele chegou à Barra do Garças em 2013 e deparou-se com o inquérito no qual as lideranças indígenas solicitavam indenização da empresa em razão dos danos que a comunidade sofreu com a queda do avião. Então Assis se pergunta: "Mas que tipo de danos seriam esses?".

A TI Capoto-Jarina é uma terra Kayapó, ou melhor, é uma terra de usufruto Kayapó, é o local onde vive o Cacique Raoni. O avião caiu nas imediações da aldeia do próprio Raoni. A comunidade foi a primeira a chegar ao local do acidente, veio pelo solo. Ela auxiliou nas buscas feitas pelas equipes de resgate, individualmente e coletivamente, e continuou trabalhando mais de um mês após a queda. Depois desse momento inicial, a comunidade indígena teve que abandonar a aldeia próxima à área da queda. Aquele espaço havia se tornado uma mekaron nhyrunkwa: uma casa dos espíritos.

O dano ambiental não foi uma variável significativa para se pensar numa indenização, embora tenha sido a categoria utilizada pelo povo Kayapó para mobilizar seus pleitos. Este era o conceito que os Kayapó conheciam do mundo do direito oficial como algo indenizável. O pedido feito pela comunidade era de que se retirassem os destroços. A Força Aérea Brasileira disse que seria uma operação de guerra e que os danos seriam maiores do que se deixassem os destroços intocados no local. A comunidade utilizava o discurso sobre o dano ambiental, porque sabiam que existia esta categoria dentro do direito brasileiro. Isso chamou a atenção do Ministério Público Federal e se tornou o fundamento principal dos transtornos dos Kayapó, foi 
uma questão espiritual, uma questão religiosa, como destaca o Procurador Wilson Rocha Assis.

Eles não podem mais utilizar essa área que tem uma extensão muito significativa. Por causa da existência de espíritos que ainda permanecem no local, eles não podem habitá-lo, em razão do grande derramamento de sangue ocorrido no espaço. Segundo uma liderança religiosa, o waangá Bedjai Kayapó, se eles a acessam uma série de fenômenos extraordinários podem ocorrer: ataque de abelhas, chuvas em grande quantidade, desorientação em área de floresta, entre outros. Wilson Assis diz que esses conhecimentos nativos, nos ouvidos dos brancos, entram como uma broca. Percebemos esta fala como a porta de entrada para um conflito cognitivo que interpreta o mesmo fato, a partir de signos distintos.

O advogado da Gol, Maurício Queiroz, diretor jurídico do grupo que controla a companhia, foi chamado para uma reunião com o MPF, a convite do procurador Wilson Rocha Assis. Em princípio, ele ouviu aquilo com desconfiança. Assis disse que sugeriu que eles contratassem um antropólogo para que compreendessem os conhecimentos nativos. Queiroz questionou: “Como você vai valorar isto?”. Assis responde: "Esta terra não pode valer para um índio menos do que para um branco". Desde o início, o procurador deixou evidente que se um acordo extrajudicial não fosse fechado, o MPF entraria com uma Ação Civil Pública.

A comunidade tentou se reunir com representantes da Gol desde 2007, sem nenhum sucesso. Os advogados da Gol só aceitaram, inicialmente, conversar com o MPF. Wilson Assis disse que, após a primeira conversa, seria necessário se reunir com a comunidade também. Ele já tinha se reunido com os Kayapó antes disso. Combinaram uma reunião em conjunto, na qual houvesse sensibilidade para que a interlocução entre atores tão distintos fosse possível. A primeira reunião foi em Goiânia, no estado de Goiás, com a Gol. A segunda, já com os indígenas, foi em Sinop/MT. Bedjai, liderança espiritual Kayapó, fez uma narrativa do que era o dano espiritual para o povo Kayapó. Maurício Queiroz disse, após o acordo, que o Bedjai foi quem o convenceu a fechar o acordo. Foi a fala de um pajé Kayapó. Assis disse que não havia nenhum precedente que tratasse de um dano espiritual.

O procurador propõe a Raoni que se marcasse uma terceira reunião e que eles dissessem neste momento quais eram os valores que a comunidade esperava receber pela queda e permanência dos destroços do avião. Wilson Assis pensou numa solução jurídica que não fosse um Termo de Ajustamento de Conduta (TAC), um instrumento jurídico específico do qual dispõem algumas instituições do sistema de justiça, como o MPF e a DPU. Nos TACs, as instituições mediadoras são partes no acordo.

No acordo que estava sendo construído, Assis compreendia que o MPF não deveria assiná-lo como uma parte interessada. $\mathrm{O}$ acordo seria firmado diretamente entre a comunidade 
e a empresa. Assis explicou isso a Raoni, respeitando a autonomia dos povos indígenas, a qual é reconhecida pela Constituição Federal e pela Convenção nº 169/OIT. Acordaram que o Instituto Raoni ${ }^{4}$ iria gerir o recurso, mas quem pactuaria o acordo seria a própria comunidade dos Kayapó. Sendo assim, quem assinaria?

O MPF pede então um laudo pericial para definir como seria o sistema jurídico Kayapó, mapeando quem seriam as lideranças tradicionais representativas do povo Kayapó. A intenção era a de que este laudo reconhecesse e apontasse quem seriam as autoridades competentes para assinar o acordo. Um ponto de dúvida surgido a partir daí seria o que fazer em relação aos jovens: não eram lideranças ainda, mas se tornariam. Poderia gerar uma tensão intergeracional. Assis compreendia que os impactos do dano também atravessariam as gerações. Os Kayapó disseram que enquanto houver memória daquele acidente, eles não poderiam utilizar a área. Paralelamente à busca de uma solução para esta variável sobre como contemplar os Kayapó de diferentes tempos, os indígenas apresentaram o valor de R $\$ 4.000 .000,00$ como indenização.

O procurador telefonou para o advogado da Gol e informou o valor. Wilson Assis acreditava que este seria o valor de início da negociação. O desenvolvimento destas etapas foi registrado, passo a passo, no Inquérito Civil Público aberto. Assis marcou uma reunião somente com Maurício Queiroz e a seguradora da empresa Gol, em Brasília, na $6^{\text {a }}$ Câmara de Coordenação e Revisão do MPF. O procurador apresentou a proposta, seus fundamentos, falou da capacidade jurídica da comunidade e indicou o valor.

A Gol havia contratado um escritório de advocacia para periciar o local de acidente, como uma exigência da seguradora, elaborou-se parecer geral quanto ao contexto do desastre e da proposta de acordo, inclusive avaliou-se o que era uma comunidade indígena e sua capacidade jurídica. Este parecer não consta no ICP. Assis disse a Maurício Queiroz que ele não via uma solução perfeita que garantisse a composição plena do conflito, mas que acreditava que aquele era o melhor caminho, sobretudo por conta da participação do MPF como entidade mediadora. Maurício aceita o acordo, integralmente, para afirmar a postura da companhia em reparar todo o dano que os Kayapó apresentaram.

Marco Paulo Schettino foi quem fez o trabalho de campo de um mês, com os Kayapó na TI Capoto-Jarina. À época em que Wilson Assis concedeu este depoimento, Schettino estava no cargo de Secretário Executivo da $6^{\text {a }}$ Câmara de Coordenação e Revisão (CCR) e era servidor efetivo do quadro de analistas da instituição. A Gol viabilizou uma aeronave pequena

$4 \mathrm{O}$ procurador destaca que o Instituto Raoni não é uma organização indigenista. Trata-se de uma organização não-governamental coordenada pelos próprios indígenas, os quais compõem o seu conselho diretor. Os brancos que trabalham no instituto são funcionários contratados pelos indígenas. 
para transportá-lo. Ele visitou quase todas as aldeias da TI Capoto-Jarina e selecionou uma bibliografia básica para compreender a organização política dos Kayapó. Foi ele quem apontou quem seriam as autoridades competentes para assinar o acordo. Raoni seria uma liderança cuja autoridade ultrapassa as fronteiras da comunidade.

O MPF participou como uma instituição cujo objetivo era trazer mais segurança jurídica ao acordo. Um mês foi mais ou menos o tempo para terminar a redação do texto. A assinatura foi feita dentro da terra indígena. Não foi um TAC. Foi a comunidade que assinou o acordo diretamente com a companhia. O Instituto Raoni é a entidade que o operacionaliza. Existem algumas regras para a gestão dos recursos, mas Wilson Assis não as explicitou, tampouco tive acesso a documentos que as determinem. É possível que elas tenham sido estabelecidas oralmente em encontros presenciais. Assis relata que esta foi uma preocupação dos próprios Kayapó, para não haver conflitos internos e dissidências dentro das aldeias. A garantia de que o recurso tivesse uma destinação positiva foi orquestrada no próprio acordo, mas sem detalhamentos que imobilizassem o que deveria ser feito com a indenização. A pedido das lideranças, o MPF, em Barra do Garças, fiscaliza a execução dos recursos. A PR-Barra do Garças é quem acompanha.

Wilson Assis diz que o acordo só foi possível por ter sido entre os Kayapó. A sua estrutura política interna é coesa. O Cacique Raoni tem ascendência forte perante a comunidade. As aldeias têm estabilidade e não se dividem constantemente. A coesão política interna à comunidade foi o elemento estruturante para que o acordo fosse mediado.

Como parte de uma instituição que compõe o Estado, Wilson Assis entende que se avança quando se compreende a capacidade jurídica da própria comunidade. O Estado precisa evitar suas posturas tutelares e criar valores para indenizações de outros povos. É um avanço compreender que as comunidades não precisam da tutela nem do MPF nem de nenhum outro órgão do Estado brasileiro. Elas precisam ser fortalecidas por esses órgãos. As instituições devem estar na retaguarda. Deve-se exigir que as empresas levem a sério as comunidades, senão as instituições estatais entrarão na luta pelo direito. É assim que ele compreende seu papel, como um agente do sistema de justiça.

Encerrando sua fala, Assis disse que há surpresas inimagináveis quando se entra nestas empreitadas em contextos culturais diversos. Ele relata que Maurício Queiroz foi muito acolhedor com as demandas apresentadas pelos Kayapó. Sua predisposição em buscar uma solução compartilhada foi determinante. Como exemplos da intensidade da relação estabelecida, ele recebeu um nome Kayapó, obteve permissão para fazer uma tatuagem Kayapó, e recebeu tratamento a partir da pajelança Kayapó.

O acordo fluiu com mais tranquilidade também por conta desta abertura para uma sen- 
sibilidade jurídica diversa, por parte do representante da empresa, o que não era esperado, a princípio. Assis diz que tenta levar conflitos para outros patamares, sua tentativa é de equilibrar a estatura dos atores que participam de um conflito. Laura Nader (1994, p. 11) é uma crítica dos modelos extrajudiciais de resolução de conflitos, justamente por entender que não há possibilidade de uma equiparação de forças. O que se difere dos casos analisados por ela para os que são mencionados nesta pesquisa é a participação de instituições estatais, internas ao próprio sistema de justiça, para intervir na defesa dos interesses das partes em vulnerabilidade. Esta é a variável que pode vir a redistribuir os pesos na balança de força.

\section{Mẽbêngôkre Kayapó I}

No dia 12 de setembro de 2019, uma quinta-feira houve uma virada nas entrevistas. Houve disponibilidade de agenda com Patxon Metuktire, neto do cacique Raoni e servidor da Funai, que acompanhou a perícia antropológica realizada em função da queda do avião da Gol. Estavam presentes: Megaron Txucarramãe e Bemoro, ambos Kayapó; Tapi Yawalapiti; e Ropni Metuktire - o cacique Raoni. Patxon pediu que fosse explicado para o Cacique Raoni o que era esta pesquisa e o que se pretendia fazer com seu povo. $\mathrm{O}$ caso foi contado e o que nos interessava a partir dele. A proposta de investigação era compreender como o sistema de justiça poderia ser capaz de gerar uma solução conjunta para um problema levado pelos indígenas, causado pelo mundo dos brancos. Isso poderia inspirar soluções para outros problemas que envolvem indígenas e outras comunidades e populações tradicionais.

Megaron parecia gostar do que era dito, pois acenava com a cabeça em concordância. Raoni se retirou pouco depois que a apresentação terminou. Então Megaron iniciou o relato sobre o que tinha acontecido, ele começou pela indenização constante que eles recebem por conta da BR-163. Depois entrou no caso. Quase tudo que ele contou conflui com os registros do processo. Megaron contou que eles foram os primeiros a chegar ao local. Essa narrativa se repete em vários depoimentos. Só havia mortos. Eles se engajaram no apoio às buscas e contataram a Funai para que enviasse seu corpo técnico. Houve derramamento de combustível no igarapé, onde a asa da aeronave caiu. Muitos destroços estavam espalhados pelo mato. A Funai não enviou ninguém para avaliar os danos e disse que partiu quando as Forças Armadas assumiram completamente as operações de busca.

O primeiro contato com a Gol foi por intermédio do advogado Maurício Queiroz. Na ocasião, o advogado disse que a prioridade era resolver as questões com os familiares das vítimas. Então, um servidor do estado do Mato Grosso, lotado em um órgão do estado responsável por assuntos indígenas em Cuiabá, mediou o contato para que mobilizassem o MPF. Megaron 
não especificou qual era o órgão. Após as primeiras tratativas, Wilson Assis procurou Megaron e os convidou para uma reunião com a Gol na cidade de Goiânia, ocasião em que seus representantes não foram. No outro momento em que se encontraram, Maurício Queiroz informou que o gasto para a retirada dos destroços seria muito alto, uma vez que teriam que alugar um avião especializado vindo da Rússia para cumprir a tarefa. $\mathrm{O}$ valor à época seria algo em torno de 10 a 15 milhões de reais. Outras pessoas foram chamadas para participar da mesa de negociação.

Megaron explicou que os espíritos das pessoas que morreram ali não sairão mais. Por isso se tornou uma mekaron nhyrunkwa, ou uma casa dos espíritos. Os Kayapó não poderão fazer mais nada naquela região, apenas cuidar para que o espaço seja respeitado. Ele sugeriu em princípio que o valor inicial a ser pedido fosse de 10 milhões. A despeito disto, o cacique Raoni pediu que fossem 4 milhões. Maurício Queiroz pediu um mês para poder negociar com a empresa. A Gol fez uma contraproposta inicial de 1 milhão e quinhentos mil reais. Em seguida fez uma nova proposta de 2 milhões e meio de reais. Na reunião que ocorreu na $6^{\mathrm{a}} \mathrm{CCR}$, negociaram o valor final e a permanência dos destroços.

Sobre a situação dos espíritos que passaram a habitar a mekaron nhyrunkwa, Megaron disse que "o Bedjai é quem entende de espírito". Orientou que conversássemos com ele. Disse que eles devem respeito aos espíritos dos mortos e que aquela casa será para sempre. Contou brevemente que os espíritos ainda gritam, conversam e atiram pedaços de pau. $\mathrm{Na}$ época das buscas, eles ficaram acampados a uma distância de $7 \mathrm{~km}$ de distância do principal local da queda. Mesmo assim, eles sentiam a presença dos espíritos. Por entender que o dano é permanente no tempo, foi perguntado se ele entendia que o acordo deveria ser renegociado em algum momento. Ele respondeu categoricamente dizendo que não. Ao fim, disse que ele teria as anotações das reuniões que os Kayapó fizeram e que poderia compartilhar. Patxon perguntou se havia interesse em ir à aldeia. Ele foi o Kayapó que levou o cinegrafista da Globo ao local do acidente e que teve medo dos espíritos.

\section{Fundação Nacional do Î́ndio}

No início de outubro de 2019, conseguimos entrevistar o indigenista Artur Nobre Mendes. À época da confecção do acordo, ele foi o representante da administração superior da Funai para articulá-lo. Ocupava o cargo de Diretor de Promoção ao Desenvolvimento Sustentável. Ele foi chamado para participar já nos encaminhamentos finais do acordo. Havia aproximadamente dois anos de debate e estavam chegando à fase de homologação do documento. A Gol concordou com a inclusão da Funai neste circuito. A instituição não assinou como parte, apenas foi partícipe que prestaria anuência, de modo a trazer maior segurança jurídica às partes, levando 
em consideração que a Funai é o órgão indigenista oficial do Estado brasileiro. Havia receio de que a Funai posteriormente se opusesse e inviabilizasse o acordo.

Artur Mendes relata que outros povos indígenas enfrentam questões semelhantes ao longo do Brasil. Ele diz que este caso poderia estruturar a jurisprudência ou, ainda que não chegue a tanto, seria referência para trabalhar com este tipo de situação. Sua leitura é a de que o dano espiritual já é uma categoria mais ampla, que engloba o dano cultural. Ambas seriam de difícil mensuração. Valorá-las é algo que entraria em um campo subjetivo. A métrica para perceber seu potencial compensatório seria a partir do sentimento satisfatório de cada povo ofendido em seus direitos. Portanto, em cada caso que envolva este tipo de violação seria necessária negociação direta entre o povo indígena e a entidade violadora.

Ainda que estejamos tratando de uma categoria de dano com suas especificidades, uma questão que imediatamente me atravessa durante nossa conversa é: a dificuldade da valoração é diferente da de um dano moral comum? Como mensurar monetariamente um sentimento que é inalcançável de forma objetiva? Artur Mendes contou outro caso, sem grandes detalhamentos, no qual uma comunidade que estava sendo atravessada por um cabeamento para internet pediu, como compensação, que a eles também fosse disponibilizado o acesso à rede virtual. A compensação, em sua leitura, resulta de um entendimento comum.

Sobre o caso específico da queda do avião, Artur Mendes, que também é antropólogo de formação, relata que os povos daquela região, denominados xinguanos ${ }^{5}$, acreditam que as pessoas que morrem e não passam por rituais fúnebres poderiam reencarnar em animais. Elas não se encaminham para onde deveriam. Suas almas poderiam reencarnar inclusive em uma planta. Este seria um entendimento comum dos povos daquela região. $\mathrm{O}$ avião se desfez no ar e as vítimas não puderam ter os rituais adequados. Para a indenização, o trauma dos primeiros indígenas que chegaram ao local do acidente também foi levado em consideração. Mesmo com a remoção dos corpos, os destroços do avião ficaram. Isto carrega historicidade e habita a memória da região. Assim, a interdição do território, o impacto psicológico dos que lidaram com a tragédia e a marca memorial na história coletiva dos povos afetados serviram de parâmetro para a ponderação de um valor.

Mendes acredita que o valor foi baixo, levando em consideração o impacto, mas que não havia margem de negociação, uma vez que foram os próprios indígenas que o indicaram. De todo modo, ele encara este caso como parte de um processo ampliado. O acúmulo de experiência colabora para dialogarem em outros casos em que houver afetação, sobretudo a partir de

5 A rigor, a TI Capoto-Jarina, ocupada pelos Mẽbêngôkre Kayapó faz fronteira com o Parque Indígena do Xingu. 
grandes empreendimentos. Ainda assim é preciso ter cuidado para não assumirem o equívoco de que o dinheiro compensaria qualquer dano sofrido.

Praticamente em todos os empreendimentos que interfiram em terras indígenas existe um impacto cultural. Qualquer empreendimento que afete uma área sagrada envolve um dano espiritual. A partir desta fala, chamaram atenção as percepções que os atores institucionais vão desenvolvendo acerca da categoria que estão construindo. Ainda que o dano espiritual não seja traduzido dessa forma, este dano pode estar nesses casos, mesmo sem ser mencionado. Por fim Mendes informou que, no caso do licenciamento da Usina Hidrelétrica de Belo Monte, a discussão sobre os impactos espirituais acompanhou todo o processo.

\section{Instituto Raoni}

Edson Araceli Santini, o coordenador administrativo e financeiro do Instituto Raoni, se disponibilizou para conversar, por videoconferência, na manhã do dia 12 de outubro de 2019. O Instituto é uma organização indígena cujo conselho diretor é integrado pelos próprios indígenas. A diretoria do Instituto é composta por cerca de 60 a 70 indígenas, que representam diferentes aldeias. Os brancos que colaboram com suas atividades são contratados para isso. À época, eram três funcionários.

Em razão do cargo que ocupa, Santini é um dos responsáveis pela execução dos recursos indenizatórios. Além de coordenador na organização indígena, é procurador do cacique Raoni. Em princípio, ele não entendia como poderia colaborar com a pesquisa, levando em consideração que não era um profissional do direito. Foi-lhe explicado que o objetivo era ouvir as diferentes percepções do caso, independentemente de ser algo com formação jurídica ou não. Como ele estava em Colíder/MT, não foi possível que a entrevista fosse realizada pessoalmente. Por ter se tornado funcionário do Instituto já enquanto as negociações estavam em curso, Santini disse que dispunha de poucas informações. Logo ao início do diálogo, ele compartilhou que, segundo a Gol, o que os convenceu a firmar o acordo foi a história narrada pelos indígenas. As questões jurídicas tiveram uma influência menor, a princípio.

O valor em si não foi discutido com Santini. O cacique Raoni já o tinha indicado. Com a liberação do recurso, o Instituto Raoni estabeleceu um plano de trabalho para organizar a utilização das verbas. Em seguida, o entrevistado contou como foi o início das negociações. Sua percepção conflui com o que os atores relataram e com o que consta no processo. Os indígenas acionaram o MPF. O procurador Wilson Assis mobilizou a Gol. Mesmo com as negociações em ritmo lento, as reuniões foram constantes entre as entidades e o povo Mẽbêngôkre Kayapó. A legislação, segundo sua leitura, obrigava a companhia a retirar os destroços — o que seria algo 
complicado. A área da queda, por sua vez, estaria contaminada por querosene, que inviabiliza o uso da área.

Os Kayapó explicaram a sacralidade advinda do espaço impactado, que agora pertence aos espíritos. Assim, as duas aldeias precisaram mudar de local: Metuktire e Bytire. Uma das aldeias - cujo nome não foi informado pelo entrevistado - precisou se mudar para uma distância de uma hora e meia de distância, que requere navegar de barco pelo rio Xingu. Isto seria algo em torno de $30 \mathrm{~km}$ acima. Santini explica que as lideranças costumavam dizer que era possível ouvir as pessoas gritando. "Essas coisas a gente não gosta nem de falar. O que eles falam arrepia." Em razão disto, os indígenas perderam o direito de entrar naquele local. O coordenador disse que é uma experiência forte e que isto comoveu os representantes da companhia Gol, que passaram a considerar a viabilidade do pleito indenizatório por dano cultural.

Após o valor sugerido inicialmente, a Gol fez uma contraproposta. O inquérito civil registra que o valor era de 2 milhões e meio de reais. Os Mẽbêngôkre fizeram uma assembleia, na qual deliberaram pelo aceite. Para a sua surpresa, durante a reunião que ocorreu na TI Capoto-Jarina, a Gol informou que pagaria o que foi solicitado, de todo modo. A partir daí, Marco Schettino foi destacado para realizar o trabalho pericial. Uma das questões era definir quem deveria gerir os recursos. A Funai ou o Instituto Raoni foram cogitados como alternativas. Ao fim, a própria Funai entendeu que era melhor que fosse o Instituto. Acordou-se que os "caciques maiores", termo utilizado pelo entrevistado, deveriam assinar. Este momento aconteceu na aldeia Metuktire.

Edson Santini relatou que os indígenas criaram bastante afeto pelo advogado da Gol, Maurício Queiroz. Ele passou a ser muito respeitado pelas lideranças, em função da atenção com a qual acolheu as demandas do povo Kayapó. Segundo Santini, ele teve muito respeito pela cultura indígena. Ambos passaram a manter contato frequente. $\mathrm{O}$ entrevistado afirmou com veemência que é preciso conhecer a realidade indígena para respeitar, para isso é indispensável ir conhecê-los em suas comunidades. Esta questão inevitavelmente retoma a importância do trabalho empírico, seja na pesquisa seja na atuação no âmbito do sistema de justiça.

Voltando à pauta da indenização, Santini diz que a Gol pagou a indenização em parcela única. À época em que conversamos, já estavam próximos de executar toda a verba. Em princípio, não havia regras pré-definidas para a utilização. Para tanto, reuniram-se em Peixoto de Azevedo/MT. Com isso, estabeleceram um plano de quatro anos para aplicarem os valores. Sua principal função foi melhorar a estrutura das aldeias. Alguns exemplos neste sentido foram: a aquisição de geradores de energia elétrica; tratores; grades; niveladores; equipamentos para trabalhar o plantio de abacaxi, pequi e mandioca; e caminhonetes para escoar os produtos gerados 
pelo povo Mẽbêngôkre Kayapó.

Em maio 2020, estava previsto o término dos recursos. Parte do dinheiro também foi utilizada para realizar eventos próprios da cultura indígena. Há uma previsão de que façam uma prestação de contas pública, ainda que isto não seja uma obrigação legal, a fim de apresentar um demonstrativo de tudo. Edson Santini entende isso como um dever moral. Os recursos também serviram para iniciarem um projeto de Sistema Agroflorestais (SAFs). A avaliação de Santini é a de que a indenização foi bem utilizada.

Sobre a administração de conflito estabelecida, Santini diz que não houve embate jurídico. O que ocorreu foi respeito entre todos. Isto viabilizou o acordo. Ele relatou que ocorreram algumas críticas às indenizações em redes sociais, mas que sequer valia a pena dar atenção a elas. Geralmente estavam ligadas a questões morais e preconceituosas contra os indígenas. A Gol, na função de entidade pagadora da compensação, fez um único pedido: o de que tentassem deixar legado para mais de quatro anos. Por fim, Santini reforçou que: a área da queda não pertence mais aos indígenas; seria difícil mensurar a dimensão do dano cultural; no local, as lideranças apontariam onde havia pessoas. Ele sugeriu que conversássemos com Megaron e com Bedjai para compreender melhor as questões espirituais.

\section{Mẽbêngôkre Kayapó II}

Em dezembro de 2019, Patxon Metuktire convidou um dos autores para ir à TI Capoto-Jarina, em um evento que ocorreria na aldeia Piaraçu. Seria um encontro entre lideranças indígenas do povo Mẽbêngôkre Kayapó. Outros indígenas também participariam. Além de apoiadores e parceiros que trabalham com este povo. O Encontro dos Povos Mebengokrê e Lideranças Indígenas aconteceu entre os dias 14 e 17 de janeiro de 2020 e reuniu mais de 40 povos indígenas e aproximadamente 600 lideranças.

Duas entrevistas foram realizadas com interlocutores: Bedjai Txucarramãe e Maialu Txucarramãe. Os Kayapó têm uma capacidade de mobilização que expressa a coesão política de um povo unido em suas demandas coletivas. Vê-los em sua organização política, que não parece se separar de suas compreensões sobre a vida e o mundo espiritual, proporciona um misto de estranhamentos entre a emoção e a serenidade. Ainda que tenham suas divergências, a sua capacidade de articulação externa e interna se manifesta de forma consolidada.

Durante o encontro em Piaraçu, o autor que esteve em campo conheceu Maialu Txucarramãe, filha do Megaron Txucarramãe. Geógrafa de formação, ela desenvolveu sua pesquisa em relação ao acordo extrajudicial decorrente da queda do avião da Gol. Não conseguimos ter uma conversa longa, em razão dos compromissos que ela tinha para cumprir durante o evento. 
Em uma fala breve, ela contou que a questão que a mobilizou em sua pesquisa foi compreender o porquê dos preconceitos dos brancos sobre o acordo, algo manifestado com recorrência no Mato Grosso, sobretudo nos dias que sucederam às notícias veiculadas na impressa. Logo em seguida, ela chamou o Bedjai para me contar sobre a sua percepção acerca do que ocorreu e precisou voltar às demandas do encontro.

Bedjai disse que estava chegando à sua casa, quando sua esposa, Wari, contou-lhe que alguma coisa caiu do céu. Algo havia explodido. Ela achava que havia sido um estouro de uma bomba. Foi possível sentir o tremor gerado pelo som. Megaron ligou pouco tempo depois dizendo que um avião havia caído nas imediações do território. "Fica pronto que amanhã nós vamos lá", disse Megaron. No outro dia cedo, eles partiram com aproximadamente 15 pessoas. Desceram o rio de barco. A aldeia mais próxima do local da queda ficava há alguns quilômetros de distância. Foram obrigados a fazer picada — abrir o caminho pela mata. Chegaram no local por volta das $16 \mathrm{~h}$. As forças armadas já estavam presentes. O comandante da operação lhes atribuiu a função de fazer as picadas onde estivessem os corpos, para que o resgate pudesse alcançá-los. Os militares iriam removê-los. Trabalharam dois dias juntos. Só então alcançaram precisamente a maior parte da estrutura do avião. Bedjai relatava constantemente que o que aconteceu "foi muito feio".

Os espíritos das pessoas ficaram repousados naquela região. Bedjai relata que, quando eles chegaram, o céu escureceu e começou a chover bastante. Segundo a cosmologia Kayapó, os espíritos não irão embora de lá, pois estão perdidos. Ficarão lá mesmo, pois não sabem para onde ir. Dez anos depois, os indígenas retornaram à área com alguns jornalistas que gostariam de fazer uma reportagem sobre a queda. Eles pernoitaram no local. A delegação ficou com muito medo, pois ouviram os espíritos gritarem. Todas as pessoas ouviram. Bedjai os orientou a fazerem silêncio para que os espíritos se acalmassem. "Os espíritos continuam lá gritando. De dia, de noite gritam mais ainda. Até hoje. O lugar deles é lá mesmo. Estão perdidos porque ninguém sabe para onde vai. É triste.”

Bedjai entende que o valor da indenização foi baixo, uma vez que o avião não irá desaparecer, a despeito de pensar que o recurso recebido foi bem utilizado. Seu impacto é permanente, além de ter poluído o rio e a mata. Houve pedaços da aeronave que caíram em um córrego próximo. Os Kayapó nunca poderão voltar a morar lá. É um local sagrado, onde não se deve mais pisar. Só voltam se alguém precisa ir, mas é preciso respeitar as mekaron nhyrunkwa. Existem outras em seus territórios. Essa é uma dos brancos. Também existem as dos indígenas. Só quem tem conhecimentos específicos sobre os mekaron pode ir. Do contrário, pode ser perigoso. Ao fim de nossa conversa, disse que ele está sempre em Piaraçu, e, se houver vontade, 
ele pode levar à área.

\section{O Acordo}

Com a conclusão do laudo pericial elaborado pelo antropólogo do MPF, Marco Paulo Schettino, o processo iniciado com o inquérito civil se encaminha para sua conclusão. $O$ desfecho: o acordo extrajudicial. A minuta foi escrita pelo corpo jurídico da Gol, e submetida ao MPF para avaliação, conforme despacho do procurador da República Rafael Guimarães Nogueira. Ele passou a acompanhar o caso, em razão da remoção do procurador Wilson Assis para outra sede do MPF. A minuta do acordo era esperada para o início de fevereiro de 2017. Seu despacho foi assinado com a data do dia 26 de janeiro de 2017. Os documentos solicitados pela companhia Gol para o MPF, como base para fundamentar o acordo foram:

(I) Cópia dos documentos societários (contrato social) do Instituto Raoni;

(II) Cópia da gravação filmográfica da reunião realizada em 28 de outubro de 2016, no prédio da Procuradoria-Geral da República, em Brasília, Distrito Federal; e

(III) Cópia da gravação filmográfica da reunião realizada em 29 de outubro de 2016, na Terra Indígena de Capoto-Jarina (MPF, fl. 127, p. 157).

Em março de 2017, após a assinatura do acordo, outro procurador da República lotado em Barra do Garças, Guilherme Fernandes Ferreira Taveira, dá início aos procedimentos para o arquivamento do inquérito civil. Em seu despacho, ele destaca o objeto do Termo de Acordo: "reparação de todos e quaisquer danos, de natureza material e imaterial, inclusive e sobretudo os DANOS AMBIENTAIS E CULTURAIS, decorrentes do acidente do Voo Gol 1907 à comunidade indígena Kayapó" (MPF, fl. 132, p. 162).

Seguindo a Diretriz n. 2, do Provimento n. 1 da Corregedoria do Ministério Público Federal (CMPF), levando em consideração que o caso chegou a um acordo no fim, este inquérito deveria ser arquivado, uma vez que a demanda foi resolvida extrajudicialmente com a elaboração de um Termo de Acordo. Além disto, caberia o acompanhamento da CCR pertinente; neste caso, a $6^{\text {a }}$ CCR. Pede-se a instauração de um procedimento para acompanhar o caso, além da juntada do acordo e dos demais documentos que o acompanham, encaminhando-o para o setor pertinente no MPF.

Por fim, o procurador da República pede que os autos sejam enviados à $6^{\mathrm{a}}$ CCR para homologação, pronunciar-se sobre o arquivamento do inquérito e pleitear junto ao presidente da Funai que ele assine o acordo antes que seja homologado, a fim de trazer mais legitimidade ao acordo. Somente após esta homologação, a companhia Gol estaria compelida a pagar a in- 
denização.

O Termo de Acordo 1/2017 foi celebrado entre o povo Mẽbêngôkre Kayapó, a companhia Gol Linhas Aéreas S.A., o Ministério Público Federal, o Instituto Raoni e a Fundação Nacional do Índio. Pelos Mẽbêngôkre Kayapó, assinaram as lideranças indicadas na planilha elaborada por Patxon Metuktire e anexada no laudo antropológico. A Gol foi representada pelo advogado Maurício Queiroz Andrade. Pelo MPF, assinaram os procuradores Rafael Guimarães Nogueira, Guilherme Fernandes Ferreira Tavares e Wilson Rocha Fernandes Assis. O cacique Raoni e Édson Santini assinaram representando o Instituto Raoni. A Funai participou como interveniente-anuente.

O texto do acordo trata das atribuições do MPF, destaca-se o seu papel na defesa do meio ambiente cultural e na proteção ao ecossistema local e aos povos indígenas atingidos. Há um breve descritivo do que aconteceu. O termo destaca a necessidade de o acordo perdurar ao longo das gerações, determinando que as lideranças que assinaram seriam representantes transgeracionais, englobando as gerações futuras. Há uma preocupação com a administração deste termo no decorrer do tempo. Fala-se expressamente que as lideranças seriam representantes atuais e transgeracionais.

A reparação pelos danos ambientais é dada tanto no aspecto material quanto imaterial. Destaca-se o art. 27 do Pacto Internacional sobre Direitos Civis e Políticos, assim como a colaboração da Gol para preservar o meio ambiente cultural. Ao mencionar o valor da indenização, diz-se que ela é pelos danos ambientais e culturais. A indenização também foi pensada para garantir que as gerações futuras tenham acesso ao meio ambiente natural conforme antes da queda do avião. O Anexo I do Termo de Acordo é o registro filmográfico da reunião do dia 29 de outubro. A FUNAI participa como órgão interveniente-anuente e a $6^{\mathrm{a}} \mathrm{CCR}$ como órgão administrativo homologatório do MPF.

O Termo de Acordo 1/2017 explica, logo no início da parte RESOLVEM, o caminho procedimental que levou ao inquérito. Sempre há o destaque para os danos ambientais e culturais. Trata-se de uma indenização compensatória, na qual a Gol teve 60 dias para depositar o valor na conta do Instituto Raoni a partir da data de homologação do acordo. O MPF ficou obrigado a emitir o Termo de Quitação de qualquer obrigação que a Gol pudesse ter em decorrência do acidente. Também é atribuição do MPF fiscalizar a aplicação dos recursos com a Funai. Há menção ao Anexo III, que contém diretrizes e premissas básicas para execução dos recursos, embora esse não conste na fonte processual disponibilizada.

O povo Mẽbêngôkre Kayapó se compromete a respeitar e cuidar para que respeitem a área e o entorno da mekaron nhyrunkwa - casa dos espíritos. A Cláusula 7.7 fala sobre o idio- 
ma do acordo, coloca-se a possibilidade de que também possa ser escrito em Gê, mas diz que deve prevalecer a versão em português para "todos os fins de direito". Para eventuais dúvidas ou disputas, o juízo competente será da Seção Judiciária de Barra do Garças, estado do Mato Grosso.

O Termo de Acordo 1/2017, segundo o texto, foi assinado em 20 de março de 2017, na Aldeia Metuktire. Patxon Metuktire assina como representante da FUNAI, embora não tenham destacado seu nome nessa posição na qualificação do acordo. Muitos dos caciques não puderam estar presentes por questões de saúde e enviaram autorizações para que representantes assinassem em seus nomes. Ao ser encaminhado para a $6^{\mathrm{a}} \mathrm{CCR}$, o acordo foi para a relatoria do procurador da República Antônio Carlos Alpino Bigonha, o qual votou pela sua homologação, destacando que o seu descumprimento poderia mobilizar o MPF a intervir. Seu voto foi acompanhado por unanimidade.

\section{ABORDAGENS EMPÍRICAS EM CAMPOS DIFERENTES}

O caso ao qual esta pesquisa se dedica tem uma peculiaridade noticiada: uma indenização por danos espirituais. A unanimidade desta categoria nativa (DURKHEIM; MAUSS, 2000) será colocada em debate, conforme os dados de campo demonstram ${ }^{6}$. Independentemente disto, há um elemento extraordinário que se destaca e faz deste um caso relevante. O caso é idiossincrático, porém está relacionado a aspectos do sistema de justiça que não se encerram em sua singularidade. A busca é por uma solução conjunta para um problema que surge na fronteira de duas percepções distintas de mundo.

Marshall Sahlins (1997, p. 190-1) interpreta que um mesmo acontecimento pode ganhar significados distintos, o que o desdobraria possivelmente em um ou mais eventos. " $\mathrm{O}$ evento é

\footnotetext{
6 Durante a apresentação dos resultados parciais desta pesquisa no $42^{\circ}$ Encontro Anual da Associação Nacional de Pós-Graduação e Pesquisa em Ciências Sociais, a Prof. ${ }^{a}$ Dr. ${ }^{a}$ Izabel Saenger Nuñez chamou a atenção para o cuidado em diferenciar as categorias nativas das categorias analíticas. As primeiras são os termos que o campo apresenta. As segundas são os conceitos que utilizaríamos para compreender as questões suscitadas pelo campo.

7 Em dezembro de 2018, durante a $31^{\text {a }}$ Reunião Brasileira de Antropologia, no Grupo de Trabalho Antropologia dos Povos e Populações Costeiras: práticas sociais, territórios e conflitos, o Professor Marco Antônio da Silva Mello era o debatedor e afirmou que provavelmente há um erro de tradução no livro Ilhas da história, uma vez que os sentidos atribuídos aos conceitos evento e acontecimento estão invertidos. Em razão de não ter tido acesso ao texto original, utilizamos a versão da fonte da qual dispus.
} 
a interpretação do acontecimento e interpretações variam" (SAHLINS, 1997, p. 191). A queda do avião é um acontecimento, objetivo e inegável. As leituras a partir disto são inúmeras, a depender da lente através da qual se observa. A criação de uma mekaron nhyrunkwa é um evento produzido a partir do acidente, sob a cosmologia do povo Mẽbêngôkre Kayapó. A companhia aérea Gol tem responsabilidade com os destroços da aeronave e com as consequências do acidente. O sistema de justiça, ao ser mobilizado, depara-se com um conflito que envolve percepções radicalmente distintas entre diferentes atores sociais e que, de uma forma ou de outra, estão diante de um conflito a ser administrado.

A questão decorrente deste cenário e que orienta este trabalho é a tentativa de compreender a forma como este conflito foi administrado. O principal problema de pesquisa é analisar as possibilidades que o constitucionalismo brasileiro viabiliza para a construção de soluções compartilhadas entre diferentes concepções de justiça. A escolha de se fazer um estudo de caso foi tomada com a intenção de investigar se a conjunção foi alcançada, ou não, neste conjunto de fatos. Não há nenhuma garantia fatalista de que os conflitos administrados pelas instituições do sistema de justiça, implicados em circunstâncias interculturais, criarão soluções capazes de abrigar as diversas leituras que os envolvidos na disputa eventualmente possam ter.

No caso dos povos indígenas, há um artigo no texto constitucional (art. 231) que prescreve a necessidade de se reconhecer sua organização social, seus costumes e tradições. Entre o que a norma determina e o que os atores que compõem o ordenamento jurídico fazem pode haver convergência ou um abismo de distância. $\mathrm{O}$ estudo de caso foi adotado por se tratar de uma abordagem qualitativa com densidade profunda, ou pelo menos se esforça para tanto.

Ao analisar este caso, procura-se entender de que forma as instituições do Estado constroem a materialização de direitos constitucionais em diálogo com a sociedade civil. Se é que isto acontece. O pleito dos Mẽbêngôkre Kayapó por danos em razão da criação de uma mekaron nhyrunkwa, decorrente da queda do avião da Gol, foi o caso escolhido por sua especificidade. Embora seja uma demanda por direitos pouco usual no contexto brasileiro, trata-se de um evento que pode se tornar um padrão comparativo de análise em outros conflitos socioambientais que envolvam povos tradicionais. São demandas por direitos em que, por vezes, não estão sequer no horizonte de expectativa dos atingidos. Na tensão entre as deliberações democráticas, viabilizadas no seio de um conflito administrado fora das cortes, e as possibilidades do constitucionalismo brasileiro, pode-se materializar direitos fundamentais inscritos na história constitucional contemporânea.

A micro-história é concebida no círculo de historiadores italianos de meados do século XX. Carlo Ginzburg é tratado como um dos autores inaugurais, ao publicar o clássico livro $O$ 
queijo e os vermes (1987). Neste trabalho, o autor se debruça sobre um único processo inquisitorial contra um moleiro do séc. XVI, denominado como Menocchio. "Alguns estudos biográficos mostraram que um indivíduo medíocre, destituído de interesse por si mesmo [...], pode ser pesquisado como se fosse um microcosmo de um estrato social inteiro num determinado período histórico" (GINZBURG, 1987, p. 25). A dedicação a um caso único permite que a atenção seja dedicada em outro patamar, com profundeza.

A leitura lenta (PINHEIRO, 2008) possibilita a percepção de detalhes que, a princípio desimportantes, oferecem explicações para fenômenos sociais que podem ultrapassar o caso. Buscar o extraordinário em um caso pode ser valoroso para as análises. "Anomalia, de um ponto de vista cognitivo, é mais rica do que a norma, porque está necessariamente contida naquela" (GINZBURG, 2019, p. 4). Carlo Ginzburg (1987, p. 79-80) demonstra como ele construiu a história de Menocchio como algo relevante. Um trabalho artesanal de tecer os fios entre os fatos que o levam a construir uma narrativa. É esta dedicação minuciosa que leva à procura incessante por pistas explicativas (GINZBURG, 2019, p. 3-4) e que, consequentemente, desdobra-se na construção de um caso.

Essa mudança na escala de análise permite que os eventos ocorridos em um determinado espaço e tempo possam ser verificados com profundidade. A partir disto é que se pode atribuir significados que extrapolem o caso. "Um dos méritos da micro-história é ter colocado, de saída, o problema da variação de escala e dos efeitos cognitivos que podem ser-lhe associados” (REVEL, 2010, p. 438).

A alternância com as escalas possibilita que situações singulares ganhem relevância explicativa em dimensões ampliadas. "[...] o que está em jogo na abordagem micro-histórica é a convicção de que a escolha de uma escala peculiar de observação fica associada a efeitos de conhecimentos específicos e que tal escolha pode ser posta a serviço de estratégias de conhecimento" (REVEL, 2010, p. 438). A redução desse campo de análise é o que permite uma verificação minuciosa do caso como um todo, o que se aproxima das orientações metodológicas que inspiram a antropologia. Não se trata de uma observação particular que encerra sua importância no local. Ao comentar o trabalho de Ginzburg em O queijo e os vermes (1987), Revel (2010, p. 439) afirma que "o indivíduo Menocchio torna-se então, por assim dizer, um marcador das reorganizações profundas vividas pela sua sociedade. [...] O que a história do moleiro Menocchio ajuda a entender são as dimensões sociais dessa experiência".

A abordagem micro-histórica "procura entender a maneira como movimentos ou transformações coletivas são possíveis, mas não a partir desses movimentos em si e da capacidade autorrealizadora que se lhes imputa, e sim da parte que cada autor toma neles [...]" (REVEL, 
2010, p. 440). No caso da queda do avião da Gol, o destaque na atuação do procurador da República Wilson Assis em coerência com o estabelecido no tempo constituinte aponta indícios da virada paradigmática que o Estado brasileiro inaugura normativamente, ao promulgar a Constituição de 1988. “A questão é, portanto, como definir as margens — por mais estreitas que possam ser — da liberdade garantida a um indivíduo pelas brechas e contradições dos sistemas normativos que o governam" (LEVI, 1992, p. 135-6).

O procurador é apenas um ator em meio a esse processo de administração de conflito. Observar todo o processo, assim como entrevistar as pessoas que tiveram disponibilidade para tanto, inscreve-se no esforço de captar distintas narrativas. Esboçam-se explicações "[...] sobre a maneira como se articulam entre si no tempo os conjuntos sociais heterogêneos" (REVEL, 2010, p. 444). Configuram-se como perspectivas individuais que ajudam a montar o caleidoscópio de cognições sob o qual se reveste um caso.

Podemos tentar entender a maneira como a fórmula estatal ganhou crédito e foi também parcialmente retrabalhada, reformulada pelo jogo das práticas sociais que ela tinha por ambição enquadrar.

Dessa constatação podemos retirar duas indicações provisórias. A primeira sugere que os atores sociais - os do passado que os historiadores estudam e os do presente - sejam recolocados no coração dos processos sociais e que tentemos compreender a maneira pela qual eles intervêm na produção desses processos. A segunda, ilustrada pelo esboço bastante sucinto que acabei de fazer sobre a construção do Estado moderno, sugere que o meio de compreender esses processos em sua maior complexidade é apreendê-los em diversos níveis (REVEL, 2010, p. 442-3).

Em torno do mesmo acontecimento, as imagens vão sendo projetadas. Os eventos são interpretados a partir de estruturas simbólicas distintas (SAHLINS, 1997, p. 190-1). Nisto reside a importância de uma avaliação holística na qual várias perspectivas são abrangidas. Tratando-se de uma análise processual, esse esforço é feito ao se analisar as diversas vozes, vontades, procedimentos e marcações temporais do processo. "O princípio unificador de toda pesquisa micro-histórica é a crença em que a observação microscópica revelará fatores previamente não observados" (LEVI, 1992, p. 139). Sem a pretensão de achar uma verdade imutável sobre o que aconteceu em um caso, buscamos percepções que, coletivamente, pudessem esboçar questões acerca de como o constitucionalismo brasileiro orquestra diversas concepções de justiça.

Cada um propõe, para o Estado, uma imagem diferente, e esta não se superpõe às imagens que podem ser constituídas em outros níveis. Nesse sentido, fazer uso de escalas de observação significa levar em consideração formas de descontinuidade presentes no mundo social efetivo. Toda realidade histórica 
maior, como é o caso do Estado, assume com certeza sua forma e seu sentido numa pluralidade de mundos sociais (REVEL, 2010, p. 443).

O problema da micro-história está fundamentalmente ligado às análises de escalas dos problemas sociais e em quais dimensões elas se inserem. Levi (1992, p. 136-7) destaca como esta também é uma preocupação da antropologia: a escala como objeto de estudo. Além de ler nas entrelinhas de um documento (LEVI, 1992, p. 160). O papel da narrativa na micro-história não é questão de mera retórica ou preferências estilísticas, mas sim um compromisso comunicativo com o leitor (LEVI, 1992, p. 152-3). Ao submeter esta pesquisa em um seminário durante o encontro da ANPOCS de 2018, as professoras Izabel Saenger Nuñez e Fernanda Bestetti de Vasconcellos destacaram que era fundamental para essa proposta dissertativa descrever as narrativas dos diferentes atores que participaram do processo. As confluências entre as abordagens da história e da antropologia foram se evidenciando à medida em que esta pesquisa foi ganhando forma.

Compreendemos que etnografia não é um método, mas sim uma abordagem que envolve estranhamento, técnica e atenção rigorosa (PEIRANO, 2014). Por reconhecer que este é um debate caro à antropologia, optamos por fazer uso de diferentes instrumentos que os exercícios etnográficos poderiam propiciar para esta pesquisa, sem que isto fizesse dela uma etnografia. Tampouco foi realizada a observação-participante nos termos de uma sociologia entusiasta das abordagens empíricas do trabalho de campo (FOOTE-WHYTE, 1980; BECKER, 2008).

Inspiramo-nos sobretudo nas propostas e práticas desempenhadas por Bárbara Lupetti (2013), uma jurista, advogada, doutora em direito, mas que ao longo de sua formação acadêmica dialoga intensamente com a antropologia, transitando entre estas duas áreas científicas, formulando problemas que interessem aos dois campos. A técnica principal utilizada foi realizar entrevistas semiestruturadas com os principais atores sociais envolvidos no caso $^{8}$.

Reconhecendo seu lugar no mundo do direito, Bárbara Lupetti (2013) compreende que os instrumentos da antropologia são capazes de desmitificar as certezas inabaláveis incentivadas entre juristas. A habilidade de estranhar o familiar é o que possibilita análises profundas acerca do funcionamento do sistema de justiça. "A etnografia permite perceber valores e ideologia diferentes daqueles que informam explicitamente os discursos oficiais do campo" (KANT DE LIMA; BAPTISTA, 2010, p. 6).

Ronaldo Lobão (2014) incentiva a prática de pesquisa empírica no campo do direito

8 O único ator social de relevância que não foi entrevistado, a despeito de ter sido convidado, foi o advogado da companhia Gol, Maurício Queiroz. Ele não teve disponibilidade de agenda. 
como estratégia que colabore para abertura dos juristas a outros conhecimentos e a estranhar suas próprias práticas. Estas leituras acerca do trabalho de campo antropológico se inscrevem na tradição de pesquisa do Instituto de Estudos Comparados em Administração Institucional de Conflitos (INCT-InEAC), coordenado pelo Professor Roberto Kant de Lima e pelo Professor Luís Roberto Cardoso de Oliveira.

Familiar para estabelecer diferenças e dele descobrir significados insuspeitados, que aparecem por contraste onde haviam sido confundidos pelo olhar opaco da familiaridade cotidiana [...] o estranhamento do familiar é um processo doloroso e esquizofrênico a que certamente não estão habituadas as pessoas que se movem no terreno das certezas e dos valores absolutos [...] estranhando o natural e familiarizando-nos com o exótico, eis o longo caminho democrático a percorrer (KANT DE LIMA, 2009, p. 13- 35).

No que tange à micro-história, recortar esse objeto de análise e reduzir a escala de observação é o que permite explorar dimensões distintas em um mesmo fenômeno social, compreendendo-as por comparação (REVEL, 2010, p. 438). Esta também é uma estratégia da antropologia jurídica (CARDOSO DE OLIVEIRA, 1992).

Marcadas as suas diferenças, Giovanni Levi (1992, p. 141) diz que "apesar de ter suas raízes no interior do círculo da pesquisa histórica, muitas das características da micro-história demonstram os laços próximos que ligam a história à antropologia”. Este argumento indica a confluência possível para realizar a análise documental e o trabalho de campo com o auxílio destas duas ciências. Curiosamente, ambas as abordagens têm uma exigência metodológica fundamental: sintetizar o objeto.

Há sempre algo a ser dito que não gostaríamos de deixar para trás, pois "ao explicitar o objeto, o método e o marco teórico, por mim escolhidos, silencio-me sobre aquilo que deixei de escolher [...]" (PINHEIRO, 2008 p. 13). Deixamos essas inquietações para outro tempo, como fios do novelo a serem puxados que inspiram a pesquisa em constante transformação.

\section{REFERÊNCIAS}

1. BAPTISTA, B. G. L. Paradoxos e ambiguidades da imparcialidade judicial: entre "quereres" e "poderes". Porto Alegre, RS: Sérgio Antônio Fabris, 2013. 
2. BECKER, H. Os outsiders: estudos de sociologia do desvio. 1. ed. Rio de Janeiro: Jorge Zahar, 2008.

3. BRASIL. Ministério Público Federal. Inquérito Civil 1.20.004.000070-2016-55. Brasília, DF: Barra do Garças, 2016. v. 1.

4. CARDOSO DE OLIVEIRA, L. R. Comparação e interpretação na antropologia jurídica. Rio de Janeiro: Tempo Brasileiro, 1992. Anuário Antropológico/89. Disponível em: http://dan.unb.br/images/pdf/anuario_antropologico/Separatas1989/anuario89_ luisroberto.pdf. Acesso em: 16 out. 2019.

5. DUMONT, L. La communauté anthropologique et l'ideologie. L'Homme, v. 18, n. 3-4, p. 83-110, 1978. Disponível em: https://www.persee.fr/doc/hom_0439-4216_1978_ num_18_3_367881. Acesso em: 14 out. 2019.

6. DURKHEIM, É; MAUSS, M. Algumas formas primitivas de classificação. In: RODRIGUES, J. A. (org.). Émile Durkheim: sociologia. 9. ed. São Paulo: Editora Ática, 2000 .

7. FOOTE-WHYTE, W. Treinando a observação participante. In: ZALUAR GUIMARÃES, A. (org.). Desvendando máscaras sociais. 2. ed. Rio de Janeiro: Livraria Francisco Alves Editora, 1980.

8. GINZBURG, C. O queijo e os vermes: o cotidiano e as ideias de um moleiro perseguido pela inquisição. São Paulo: Companhia das Letras, 1987.

9. GINZBURG, C. Disciplines, Serendipity, Case Studies. European Review, v. 28, n. 1, p. 11-7, Feb. 2019. Disponível em: https://doi.org/10.1017/S106279871900022X. Acesso em: 03 nov. 2019.

10. KANT DE LIMA, R. Ensaios de Antropologia e de Direito: acesso à justiça e processos institucionais de administração de conflitos e produção da verdade jurídica em uma perspectiva comparada. 2. ed. Rio de Janeiro: Lumen Juris, 2009.

11. KANT DE LIMA, R. Sensibilidades jurídicas, saber e poder: bases culturais de alguns aspectos do direito brasileiro em perspectiva comparada. Anuário Antropológico, p. 25-51, 2009-2/2010. Disponível em: https://journals.openedition.org/aa/885. Acesso em: 22 out. 2019.

12. KANT DE LIMA, R.; BAPTISTA, B. L. O desafio de realizar pesquisa empírica no direito: uma contribuição antropológica. In: ENCONTRO DA ABCP (Associação Brasileira de Ciência Política), 7., 2010, Recife. Anais... Recife, PE: [s.n.], 4-7 ago. 2010. Mimeo. Disponível em: https://app.uff.br/riuff/handle/1/8005. Acesso em: 07 nov. 2019.

13. KANT DE LIMA, R. Como a Antropologia pode contribuir para a pesquisa jurídica? Um desafio metodológico. Anuário Antropológico [Online], v. 1, p. 9-37, 2014.Disponível em: https://periodicos.unb.br/index.php/anuarioantropologico/article/view/6840. 
Acesso em: 05 nov. 2019.

14. LEVI, G. Sobre a micro-história. In: BURKE, P. (org.). A escrita da história: novas perspectivas. São Paulo: Editora da Universidade Estadual Paulista, 1992. p. 133-61.

15. LOBÃO, R. Cosmologias políticas do neoliberalismo: como uma política pública pode se transformar em uma política do ressentimento. Niterói, RJ: Editora da Universidade Federal Fluminense, 2010.

16. LOBÃO, R. Notas em favor de um programa de pesquisa de antropologia no direito em contextos de jusdiversidade. Democracia y Derechos: Red Universitária sobre Derechos Humanos y Democratización para América Latina, n. 5, p. 43-68, maio 2014. Disponível em: https://app.uff.br/riuff/handle/1/12037. Acesso em: 14 ago. 2019.

17. NADER, L. Harmonia Coerciva: a economia política dos modelos jurídicos. Revista Brasileira de Ciências Sociais, n. 29, p. 18-29, 1994. Disponível em: http://anpocs. com/images/stories/RBCS/26/rbcs26_02.pdf. Acesso em: 10 nov. 2019.

18. PEIRANO, M. Etnografia não é método. Horizontes Antropológicos, Porto Alegre, RS, n. 42, p. 377-91, jul./dez. 2014. Disponível em: https://www.scielo.br/j/ha/a/ n8ypMvZZ3rJyG3j9QpMyJ9m/?lang=pt. Acesso em: 13 set. 2019.

19. PINHEIRO, D. A. R. Direito, Estado e religião: a Constituinte de 1987-1988 e a (re) construção da identidade religiosa do sujeito constitucional brasileiro. Belo Horizonte, MG: Argvmentvm, 2008.

20. REVEL, J. Micro-história, macro-história: o que as variações de escala ajudam a pensar em um mundo globalizado. Revista Brasileira de Educação, v. 15, n. 45, p. 434-44, set./dez. 2010. Disponível em: https://www.scielo.br/j/rbedu/a/k5MsKMHv6ZQvPsF5vqvdkpB/ abstract/?lang=pt. Acesso em: 29 out. 2019.

21. SAHLINS, M. Ilhas de História. Rio de Janeiro: Jorge Zahar Editor, 1997.

\section{Lucas Cravo de Oliveira}

Mestre em Direito pela Universidade de Brasília. Graduado em Direito pela Universidade Federal Fluminense. ID ORCID: https://orcid.org/0000-0002-9722-8698. E-mail: cravo.lucas@ gmail.com. Colaboração: pesquisa bibliográfica, pesquisa empírica, análise de dados, redação.

\section{Douglas Antônio Rocha Pinheiro}

Professor Adjunto do Programa de Pós-Graduação em Direito (Mestrado e Doutorado) e da Faculdade de Direito da Universidade de Brasília. Doutor e Mestre em Direito pela Universidade de Brasília. Graduado em Direito pela Universidade Federal de Goiás. ID ORCID: https:/orcid. org/0000-0002-0970-0842. E-mail: darpinheiro@unb.br. Colaboração: pesquisa bibliográfica, análise de dados, redação. 
Ronaldo Joaquim da Silveira Lobão

Professor Associado do Programa de Pós-Graduação em Sociologia e Direito (Mestrado e Doutorado) e da Faculdade de Direito na Universidade Federal Fluminense. Doutor em Antropologia pela Universidade de Brasília. Mestre em Antropologia pela Universidade Federal Fluminense. Graduado em Ciências Sociais pela Universidade Federal Fluminense. ID ORCID: https://orcid.org/0000-0002-6532-0262. E-mail: ronaldolobao@yahoo.com.br. Colaboração: pesquisa bibliográfica, análise de dados, redação. 